\title{
Inside the Outsider: The Reappearance in Chinese Literature of a Long Absent Type of Character
}

ANNE WEDELLWEDELLSBORG

University of Aarhus

Of course there are some examples of individuals who crave passionately for a more meaningful existence. But they have to express their inner feelings furtively, out of sight of society. If they admit their beliefs openly, they will simply be seen as "negative examples" by the community. So these people continue to be oppressed.

The above quotation, describing the Chinese outsider, is taken from the Hong Kong intellectual Sun Longii's book, The Deep Structure of Chinese Culture, published in Hong Kong in 1983. This work, together with The Ugly Chinaman by the Taiwanese essayist Bo Yang, has been widely circulating in China, attracting much attention in intellectual and artistic circles. ${ }^{1}$ Both of them attempt to confront and analyse the negative impact of Chinese culture on its people, and, on that basis, to discuss what it means to be Chinese in the twentieth century. ${ }^{2}$ They were received in China as highly relevant and provocative contributions to the search for identity, nationally and individually, which has been the main characteristic of the literary scene in recent years. In this article it is intended to take a closer look at this search, through the particular angle of the outsider, as he or she is represented in contemporary fiction. But before giving my definition of an outsider, a few general remarks about the interest in national and individual identity are called for.

The search in literature for national identity has been most conspicuously expressed in the so-called "root-seeking" (xungen) literature, prominent since 1984, which consciously tries to rediscover some traditional Chinese elements, mainly Daoism and Buddhism, but also tribal cultures, primitive myths and folklore. ${ }^{3}$ This search, as well as being a psychologically understandable response to the tremendous and sudden influx of Western culture and to the whole process of economic modernization, has also been triggered off by the urge to find the roots and causes of the Cultural Revolution. And in fact a sense of the necessity of enquiring into deep-rooted traditional values existed in avant-garde circles well before the large-scale cultural opening of 
the eighties. The positive approach of the exponents of the recent root-seeking literature, like A Cheng and Han Shaogong, can be said to be complemented by the critical attitude inherent in many stories published in the pioneering unofficial magazine Jintian (Today) already in 1978-80. Several stories by writers such as Zhao Zhenkai and Chen Maiping for example, imply a subtle criticism of the traditional virtues of compliance and adjustment. ${ }^{4}$ The "debate" over national character underlying a significant part of the literature of the post-Mao era is not even something exclusively characteristic of this period. The present debate can in some ways be seen as a continuation of earlier discussions in the fifties and sixties around the type of $A$, though widely divergent in regard to not only concrete issues, but also frame of reference and terms of discourse. ${ }^{5}$

By contrast, the search in literature for individual identity, as something apart from collective identity, is a new phenomenon particularly belonging to the latest decade, with no real precursors in the previous years of the People's Republic. Looking at the more interesting part of what is in China broadly termed "searching" (tansuoxing de) literature, it is clear that whereas the search for national identity may include or be linked up with a more personal search, there are many examples of literary figures groping to define themselves without even indirectly referring to questions of national identity.

Here I shall present some of these stories which in one way or another touch upon the individual's attempts to understand and cope with the complexities of his or her own existence. ${ }^{6}$ I shall not attempt any in-depth literary analysis, but rather - as mentioned above - focus on one particular type of fictional character who, after many years of absence, seems to have reentered Chinese literature, and who, by definition, stands apart from the rest: the outsider.

\section{What Is an Outsider?}

In using the term "outsider" it is important to note that it should in this context be understood in a purely psychological sense, not in the sense of a social outcast. The outsider is a well-known figure in modern Western literature, and not to be confused with the romantic hero of predominantly 18th and 19th century literature. ${ }^{7}$ The romantic hero is also a solitary figure, defying the norms and often epitomizing the conflict between self and society (or perhaps between qing and $l i$ ). But in contrast to the outsider he is very conscious about his situation, he acts or even fights for his conviction. An outsider then, is 
someone who is different, alienated from the immediately accepted values of his or her surroundings, and therefore not wholly integrated in the community, at least not on a mental level. The outsiders are often outsiders because of an insight, a knowledge, however vague or subconscious it may be, that there is, or should be, an "other reality" more meaningful than that of their present ordinary life. In fact the daily tasks and pursuits which are real to other people often give the outsider a sense of unreality. He feels or knows something other people do not see or do not care about - whether this knowledge or feeling is that there is more to life than daily routine, or that China is a man-eating society. One can say that a person becomes an outsider, when he or she becomes alive to certain questions, which make it impossible to remain just an ordinary well-adjusted social being in the particular context in which he or she is placed. In Sun Longji's phrasing it is someone who craves passionately for a more meaningful existence. But this passionate craving may have become distorted, suppressed or sublimated, or it may reside in the subconscious.

So the outsider is somehowlonely, a stranger who lives in his own world. He does not take full part in the community, or is split, so that an important constituent part of him is at odds with the conventional community. Particularly the modern outsider often has a divided mind, he is a person split between the wish to become integrated and the impossibility of eliminating that "other reality" which has become an obstacle to his integration.

One might choose to consider a fictional character to be an outsider, in the specific context of the literary text in which it appears or against the broader background of the society in which the text is produced. Here the concern is only with the former, where the outsider character is basically out of harmony with his fictional surroundings, and where the development of the plot is not towards an establishment of harmony.

Before turning to the present let us begin with a quick glance at a few of the most famous persons in earlier Chinese literature who could fit this definition of the outsider. Thus Jia Baoyu of Dream of Red Mansions could be one of the examples from traditional literature. He certainly knows the "other reality" both in an emotional and in a religious sense - and his values are different from those expected of him. Though he initially lives in harmony in the world of women, he also turns out to be eventually unable to integrate the two realities.

As one jumps to this century, $\mathrm{Lu}$ Xun is of course the creator of that supreme outsider - the Madman, whose madness, as the reader understands, is the 
ultimate proof of his sanity. ${ }^{8}$ Just a few years later Yu Dafu portrayed a completely different kind of outsider in his famous story "Drowning" - the romantic, self-pitying and self-loathing young man in a foreign environment, who ends up comitting suicide. ${ }^{9}$

Now, in a sweeping generalization, this writer would venture to say that in the period 1949-76 the outsider all but disappears from Chinese literature. Despite the conspicuous presence of fierce class struggle the fiction of these years is characterized by a harmonizing tendency which tends to eliminate outsiders the moment they appear, either by letting them accept the values of the collective, or, in the case of heroic persons, letting the collective conform to their outlook. In both cases the result is a merging of values and the "outsider" ceasing to be an outsider. Actually the whole point of the plot often seems to be to show how the outsider becomes an insider.

\section{Female Outsiders}

But during the last few years the lonely figure of the outsider has again become recognizable in Chinese literature. He or she is represented by very different types of persons, in very different situations, and their particular insights or awarenesses of a "second reality" take on very different shapes. It is perhaps not strange that in women's literature - one of the remarkable trends of the early post-Mao literature - one finds a number of female outsiders, caught in the dilemma between their wish for fulfillment as social and as emotional beings. To mention a few of the most well-known: The middle-aged woman in Zhang Jie's sentimental story "Love Should Not Be Forgotten" who decides to live in the "other reality" in the form of her love for a man she cannot have, forever regretting that she initially gave in to the accepted norms of the immediate reality; ${ }^{10}$ and the protagonist of "Northern Lights" by Zhang Kangkang, for whom the northern lights act as a metaphor for the other true reality, which plays a part in guiding her choice of husband. ${ }^{11}$ The three single women in Zhang Jie's "The Ark" are also a kind of outsiders, who have deliberately chosen to live beyond the norms of society with all the contradictions that follow. ${ }^{12}$

One very good example is "The Dreams of Our Generation" by Zhang Xinxin. ${ }^{13}$ The outsider protagonist is a young woman who lives in an unhappy, arranged marriage with a rather ignorant husband. Her longing for something more - to some extent simply a longing for a closeness and warmth that she 
does not find in her marriage - is projected on a "he", a boy who many years ago helped her when she was in great fear and showed her some feeling. Thus for her the "second reality" takes the shape of a dream or fantasy, which helps her escape triviality, go through the tiresome daily routines of housework and cope with the difficulties of living in a cramped space. At the same time, this dream or insight that things should be different is precisely what alienates her from her surroundings. At the end of the story her romantic dream is brutally shattered when she finds out that her neighbour, whom she detests, is in fact identical with the original boy of the reminiscences upon which she has built her fantasy. But although the story stops at the point where she has realized that the particular image she has created in her longing for a "second reality" is an illusion, the insight into the existence and necessity of that "other reality" remains valid, and no harmony is achieved between the outsider and her surroundings.

The bulk of this women's literature does however, in my opinion, belong to what can be termed "problem literature", i.e. literature written with a specific reference to current social problems. Artistically much improved compared to earlier periods though it may be, it still operates within certain limits, and tends to be rather predictable in the development of the plot. ${ }^{14}$ In order to go a bit deeper and get a more complex picture of the ways in which the outsider characteristics may manifest themselves in Chinese individuals of the 1980s, I shall now go on to consider some stories by three of the most original contemporary mainland Chinese writers, Zhao Zhenkai (better known as the poet Bei Dao), Can Xue and Zhong Acheng. Their writings differ greatly from one another, but they all combine a highly individual literary style with a personal vision of life.

\section{Zhao Zhenkai}

Zhao Zhenkai's short story "Moon on the Manuscript" has something in common with "The Dreams of Our Generation", but is much more sophisticated. ${ }^{15}$ The outsider in this case is a man in crisis, an author who has lost the ability to write, thus epitomizing a problem common to many outsiders - the difficulty of communicating. Like the protagonist in the former story he is a divided personality, unable to integrate the two realities. His insight into the existence of another, true reality also makes him resort to dreams of the past, in this case very clearly the temps perdu - idyllic images of an uncomplicated 
childhood by the sea as the son of a fisherman. He wishes to be normal and simple, envies ordinary people with ordinary jobs, who can just go and have a drink or two after work. He longs for things to be concrete, tangible, and yet at the same time reacts against people who have clear, down-to-earth, realizable ideas about happiness. $\mathrm{He}$ is split between on the one hand his wish to conform, to do what is expected of him, to achieve the outward success of a famous writer, i.e. to succeed in the generally accepted reality, and on the other hand his longing for authenticity, for the courage as a true artist to stake everything in a single venture, for the freedom and independence which the seagulls symbolize for him. In the end social pressures and material factors make it impossible for him to assert the part of himself which wishes to be loyal to the higher reality. He decides to more or less plagiarize the first literary attempt of a young student, thus betraying not only another person, but also his own insights into the "other reality". Thus, though conforming on the surface, he remains an outsider, feeling sick and filled with self-contempt. The story is permeated with contrasting pairs of symbols and images, such as fish and oysters in the sea versus goldfish in a basin and fish as a gourmet dish, primitive man concerned with basic needs versus modern urban man troubled by petty affairs, sun versus moon, and crescent moon versus full moon, reflecting the opposite concepts of childhood and adulthood, genuine art and social prestige/plagiarism, authenticity and artificiality, integrity and adjustment. The whole narrative can thus be seen as an exposition of one of the major themes of all fiction: the conflict between self and civilization.

The literary theorist Norman Friedman, in an analysis of Albert Camus' LEtranger has tried to define what may be the crucial problem in stories in which civilization is seen as a threat to the self, by way of distinguishing between two realms of action, two principles of authority. ${ }^{16}$ Friedman's approach is highly applicable to Zhao Zhenkai's story and adds an extra dimension to it (and to our understanding of the outsider's predicament in general).

First, Friedman says, there is the realm of practical expediency, of socialization and duties, which deals with means, with the problems of coordinating the business of society. Secondly, there is the inner, private realm of values and ends, rather than instrumentalities. This second sphere has to do with what life signifies to the given individual, over and above the satisfaction of his material and practical needs, and refers to pleasures, beliefs, personal conscience, artistic experience, etc. The principle of authority in the first realm is the force of necessity: one has to do certain things in order to survive and 
prosper materially. Correspondingly, the principle of authority in the private realm is the force of conviction: that one wants to do certain things for the sake of fulfilling non-material needs, for their own sake. The point is that each of these forces is compelling in its own way, and the problem arises when one of them is mistaken for the other with the result that claims are made upon us in the name of an inappropriate principle. When this happens, one realm intrudes upon the other, the proper area of power in the other is threatened and diminished, and one's sense of reality becomes distorted. In this way, confusing the two realms results in destructiveness and absurdity. ${ }^{17}$

What happens for the writer protagonist in "Moon on the Manuscript" is precisely that the two realms get mixed up and confused, further accentuated by the fact that the second realm, that of private conviction and artistic creativity, is closely tied to the first, that of material and social necessity, through his position as a writer. It is implied in the story that if only the principle of inner authority could maintain autonomy, if he did not have to let his art be directed by, not only social prestige, but also by material wants such as better housing, washing machine, etc., he might get over his mental block.

So Zhao Zhenkai's story is a dramatization of the conflict between the two realities, or in Friedman's terminology, the two realms. Instead of having the two naturally integrated into his life or realizing that they should, in a sense, be kept separate, the writer protagonist allows the principle of necessity to make claims upon the realm in which only the principle of conviction should rule. He decides to plagiarize, even at the same time trying to deceive himself into believing that he is writing his own story. As will be seen later in this article, the outsider protagonist in this story makes an interesting contrast to another, more famous, outsider figure: A Cheng's "The King of Chess".

We shall now turn to a completely different kind of story, also written by Zhao Zhenkai, called "No. 13Happiness Road". ${ }^{18}$ This is no character study, no psychological portrait of a tormented individual. Instead the protagonist could be said to be merely symbolizing an outsider, and the whole story is rather like an allegory of the unsocialized individual and the totalitarian state, of man in a society where "no one knows anyone and no one understands anyone". ${ }^{19}$ It is a rare piece of surrealist writing, Kafkaesque in its mixture of recognizable everyday detail and nightmarish absurdity. The outsider in this case is a journalist who sets out to discover what is hidden behind the dilapidated wall of No. 13 Happiness Road. The narrative emanates a kind of pitchblack humour, developed through a number of heavily satirical and extremely 
funny scenes, in which the protagonist seeks out various people and representatives of the Chinese bureaucracy - all concerned with their own futile affairs - in order to ask his seemingly innocent question. The story may be interpreted in several ways, but one is to understand No. 13 Happiness Road as a metaphor for the unknown, the undefined. So what sets this outsider apart from his surroundings is his quest, his search for something no one knows about. He becomes obsessed by this "other reality" represented by Happiness Road. But "that which no one knows about is a state secret", ${ }^{20}$ so the security chief tells him. He who investigates the terra incognita, that which is not already known and defined by the authorities, is a lunatic, and the journalist ends up in the madhouse, just when he has found out that No. 13 Happiness Road is completely empty, a vast nothingness, an open space. The story ends in a kind of circular irony, by the protagonist realizing that he himself is actually within the walls together with all the other madmen running in circles along the walls. A less subtle interpretation is to simply understand No. 13 Happiness Road as the asylum from which there is no escape, and where the system places outsiders such as children and people with curious, independent minds.

Whatever the possible meanings, and despite the special quality of text and plot, which makes it rather unique among contemporary short stories, it certainly presents an outsider in my broad definition of the word. One who is different and disturbed, and whose dedication to something other than the accepted norms of the surroundings makes it impossible for him to remain an ordinary well-adjusted person.

\section{Can Xue}

From Zhao Zhenkai's curious journalist, defined by the totalitarian state as a madman, we come to a more complex kind of lunatic: the girl in Can Xue's "The Little House on the Mountain". 21

Can Xue is a young Hunanese woman writer, who has attracted some attention in avant-garde literary circles in recent years for her strange writing. She is, for example, the favourite writer of the so-called "dark horse" of Chinese literary criticism, Liu Xiaobo. ${ }^{22}$ She has published one novel, a few novellas and a number of very short short stories, all written in her highly individual, dream-like manner. ${ }^{23}$ She herself admits admiration for Marquez and Kafka, but definitely has her own weird style. Most of her works are surrealist presentations of mental distortion, and her favourite theme seems to 
be family relations. She is a master of unappetizing detail and grotesque exaggeration, often, however, relieved by irony and humour. It is a characteristic trait of her narrative technique that what may be interpreted as inner troubles is often represented by its corresponding outward physical manifestation. ${ }^{24}$

"The Little House on the Mountain" records a person's mental split. The story reads more like the raw account of a dream than a polished work of art, and is not really very successful as literature. But it does represent a new and awkward and in a Chinese context maybe a particularly uncomfortable way of presenting and revealing the angst and frustrations resulting from limitations of personal freedom. ${ }^{25}$

The whole story is told and seen from the point of view of the first personnarrator. This limited point of view, that of a mentally distorted person, is watertight - allowing no ambiguity in the context of the text itself. The narrator's field of vision, her perception of what is going on, being said, etc., is almost like a cage in which the reader is being held, never allowed a double vision, a glimpse of things from the outside. This means that everything, including conversations recorded in direct speech, comes to the reader through the filter of the narrator's disrupted mind. Only extra-textual knowledge (of what constitutes normality!?) allows the reader to recognize her abnormal state.

The picture she presents is: She lives in a house with her parents and her little sister, who all persecute her, misunderstand her and try to prevent her from doing what she wants to. The logic is that of a nightmare, where the father turns into a wolf, a fat worm is crawling in her mother's head and the narrator can hear the rattling of ice-cubes in her own stomach. Actually all the four members of the family seem isolated each in their own haunted mind, at the same time as they are oversensitive: the sound of the protagonist opening and closing her drawer gives her mother such a headache that she has to put her head into cold water, almost catching pneumonia. The light from her daughter's room at night irritates her so much that she hears the sound of drumbeats in her blood vessels. The piercing eyes of mother and sister make the narrator's skin swell and give her red spots.

The I of the story is a true outsider, albeit of a very special kind. She definitely feels separated from the rest of her family, and is unable to communicate her insights to them. She alone knows how things really are, sometimes trying to make them understand, but mostly fearing them, seeing through them and their plot against her. Her particular insight or knowledge of "another reality" 
is symbolized in the story by the image of a little house on the mountain behind the house where she lives, in which a person is locked up. Sitting quietly in her room with her hands on her knees she can clearly see the house, and the person inside it, who is throwing himself against the door. But when she tries to climb up the mountain to find it, she is dazzled by a blazing white light and must give up. So the outsider's insight in this case is an insight into her own situation, or more generally perhaps, into the futility of human endeavour, an insight which she is unable to grasp, at the same time as it exists clearly in her mind.

In her "real" life her most important occupation, almost her obsession, is to tidy up and make order inside her drawer, which is filled with her "dearest belongings": dead winged insects. The drawer symbolizes her subconsciousness, and the flying insects, now dead, are symbols of her own crushed demands for freedom and creativity. Just as the person locked up in the little house on the mountain is throwing himselfagainst the door, these insects have clashed against the wind ows and walls of the house in which she lives with her family. At the end of the story a large swarm of longicorns comes flying in through the window to her parents'bedroom, clashing against the walls; biting her mother's feet so that her legs become like pillars of lead. Just as the I-narrator's subconscious demand for freedom is symbolized by flying insects, so her rational, logical self is symbolized by another favourite belonging: her chess set, which the family keeps burying beside the well, and which she tries to dig up every night.

For the outsider in "The Little House on the Mountain" the insight into the "true" reality has not just led to inner conflict, as was seen. in Zhao Zhenkai's psychological portrait of the tormented artist. One can say that for Can Xue's main character, the insight into her own situation has somehow been too much to cope with, and has resulted in a mental split, preventing her from consciously realizing her predicament, not to mention doing anything about it.

There is another story by Can Xue which can be mentioned briefly, namely "Soap-Bubbles on Dirty Water", a grotesque and absurd tale, yet relatively straightforward compared to Can Xue's other writings. ${ }^{26}$ A young man lives alone with his absolutely disgusting, nasty and unappetizing mother. She scolds and bullies him all the time, and constantly accuses him of wishing that she will suffocate in the small kitchen in which she has placed her bed. She also wants to marry him off to a thirty year old spinster with hemorrhoids in order to secure her guanxi to a minor leftist official. One day the mother happens to spill some tea on her face and the son notices a mass of bubbles as her face 
seems to dissolve. "Seized by the devil", he fetches a big bowl of soapy water and asks her to wash, then locks the door from the outside. When he later returns there is no trace of his mother, only a bowl of black water with bubbles on top. As the neighbours start coming in, he jumps out into the street, his mother's shrill voice reaching him from the depth of the bowl. He suddenly starts to bark and ends up setting his teeth in the flesh of an old man.

The metamorphosis of the mother can be seen as wish fulfillment on the part of the young man. But instead of being set free, he himself in yet another metamorphosis changes into a mad dog, i.e. he becomes the embodiment of all his pent-up aggression, the morale of the story being that you never escape. The suppression of child by mother (i.e. by the family system) is of such a nature that the grown-up person himself turns into a despicable, destructive being once she is away, and her voice (i.e. her influence) continues to follow him.

It may be a bit forced to see this story as one about an outsider, but one might understand the young man as an outsider whose "insight" consists in realizing that his mother (i.e. the system that suppresses and limits him) is nothing but dirty water, that he can actually make her (it) dissolve; - the black irony being, however, that he is unable to use this insight, since he himself has already become distorted by that which suppressed him.

\section{A Cheng}

From Can Xue and her world of lunacy and disharmony I shall move on to A Cheng, a writer as different from her as at all possible in terms of themes, narrative method and world outlook. ${ }^{27}$ From most of A Cheng's work, though it deals with fundamental problems and is not without drama, emanates an inner calm and a kind of serenity rarely found elsewhere in contemporary Chinese literature. Thus this presentation of Chinese outsiders can be concluded by showing that it is possible to be an outsider in China (or in Chinese literature at least) without suffering from mental conflicts.

From Can Xue's mad characters - kuangren, it is a relief to turn to a daizi the chess maniac, i.e. the title person of A Cheng's "The King of Chess". ${ }^{28}$ This much celebrated novella, his first published story, is one in the important wave of stories based on the experiences of the sent-down youth during the Cultural Revolution. It is also held to be one of the first examples of the "root-seeking" literature. Outwardly a very simple story, it is in fact a closely-knit and 
philosophically many-layered text. It is about a young man, Wang Yisheng, who, in a world of disaster, hunger and absurdities, has managed to preserve his dignity by devoting himself to the ancient, traditional game of chess (xiangqi). On the immediate level one may say that he, too, is a bit of a madman in his single-minded pursuit of the spiritual concentration to be found in the game. He does not care about the rituals of conventional social behaviour (shown by his indifference to saying good-bye to his sister at the station, his wanderings, his absent-mindedness, his spontaneous applause at the play, etc.), and he has his own concepts of right and wrong. But he is no split personality. He is presented as an integrated person with a natural capacity for friendship, and although his mentality may be at odds with his surroundings in the wider sense of the accepted norms at the time when the story is supposed to take place (late sixties-early seventies) there is no unresolved conflict in the context of the story itself.

One might ask then, if the chess king. Wang Yisheng, can really be called an outsider according to the definition given above. He can. He is certainly no romantichero, he does not fight against anything or for any conviction, he does not try to persuade others. He is an outsider who has managed to hold on to his - mystical - insight into the "other reality". One could even be tempted to say that he has chosen this "other reality" to the extent of suppressing both his physical and his emotional needs. But that is not really how it is. Wang Yisheng is almost as concentrated in his eating as he is in his chess playing. In a sense "The King of Chess" is a story about a man's basic needs: food and "something more" (one might argue that sex is conspicuously lacking). The story is actually as much about food as about chess, and all the important characters' different attitudes to food are carefully described (the painter's disregard of it and preference for drink, Ni Bin's taste for delicacies, the narrator's almost artistic ability at cooking). It is therefore interesting to compare it with Zhao Zhenkai's "Moon on the Manuscript" analysed above, which - linked up with the particular conflict between self and civilization - also deals with the relationship between material and spiritual needs. Applying Norman Friedman's approach to "The King of Chess" adds an extra dimension to the obvious difference between the protagonists of the two stories.

Thus in "The King of Chess" one can read the two basic human needs, food and "something more" - represented by chess, in a wider context as symbols of the two realms, which should each be governed by its proper principle of authority. If the tragedy of the protagonist in "Moon on the Manuscript" is the way in which the two get mixed up, resulting in loss of integrity and self- 
esteem, then the fulfillment, contentment and integrity of Wang Yisheng on the other hand is closely connected with his knowledge that it is essential to keep the two separated. Although food as a fundamental physical requirement may influence his chess playing (he plays badly if he has not eaten), he is very conscious about not allowing the two to interfere, as they are both necessary to his life. This is explicitly shown throughout the story by his refusal to play when there is any kind of deal involved, in the lesson of the old man, and his own conviction "never to play chess for a living".

Another striking contrast between Zhao Zhenkai's and A Cheng's stories is the two main characters' relationship to nature. In "The King of Chess" nature is right there, the "natural" environment for man, neither strange, nor in opposition to man, nor something romantic or nostalgic. In "Moon on the Manuscript", nature, i.e. the sea and the beach, has for the urban writerprotagonist become the symbol of something lost, a harmony and fulness from which he is forever separated, a lost realm that can only exist in his memories.

\section{Conclusion}

The outsider figures in the works presented above by Zhao Zhenkai, Can Xue and $A$ Cheng are not only very different personalities in terms of temperament, social situation and the specific problems they face. They are also presented in widely different textual contexts, in terms of style, imagery and literary structures. And among them only one, the king of chess, relates specifically to a part of the national Chinese culture (Daoism).$^{29}$ Yet they all share a vision of something different from the ordinary, something which cannot be immediately communicated to their surroundings, and which makes them unadjusted. Their visions and insights take on individual shape and contents, and influence their lives in various ways, mostly negatively, as they cannot be reconciled with the norms and expectations of others. In the instances given above the effects range from inner conflict (Zhao Zhenkai) and mental split (Can Xue) to spiritual harmony (A Cheng). The outsider's vision may turn into (or reveal itself as) nostalgia, escapism, disillusionment, paranoia, insanity, mysticism or religion, and it may be sublimated, distorted or suppressed. The remarkable thing is that these characters, in contrast to characters in the fiction of previous years, are allowed - by their creators - to persist and remain outsiders in the eyes of the readers. 
The question is, why is this so? The first and obvious answer is of course that the scope for literary expression in China has been greatly extended. But there is probably also a deeper one. The "outsider experience" is a particularly concentrated part of the process of recognizing one's identity. It is hardly a coincidence that the main outsider figures considered here all in one way or another belong to the category of either artist, maniac or madman, people who are more acutely sensitive and have more direct access to the other "truer" reality than ordinary persons. Speaking in very broad terms, the mental duplicity of the outsider is one of the - paradoxical - responses to the painful, and also inspiring, "modern experience", i.e. that the individual human being is essentially alone, and, for better or worse, responsible for itself, without recourse to any all-embracing community or shared ideology. ${ }^{30}$

Anne Wedell-Wedellsborg is Associate Professor,Institute of East Asian Studies, University of Aarhus.

\section{NOTES}

1 Sun Longji, Zhongguo wenhua de 'shenceng jiegou' (The deep structure of Chinese culture) (Hongkong 1983). The excerpt here is from a translation in Geremie Barmé and John Minford (eds.), Seeds of Fire: Chinese Voices of Conscience (Hongkong: Far Eastern Economic Review Ltd.,1986). Bo Yang, Choulou de Zhongguo ren (The ugly Chinaman) (Taibei 1985), contains the original speech about "The Ugly Chinaman" given in America in 1984, plus other essays. English translation of the speech in Renditions, No. 23 (1985). Abridged translation based on the book version in Barmé and Minford, op.cit. In an interview published in the Hongkong Liaowang overseas edition July 27, 1987, Song Muwen, Deputy Head of the State Media and Publications Office, speaks rather favourably of the book and says that the only problem connected with its publication in China has been that too many publishing companies have published it simultaneously. See Survey of World Broadcasts FE/8640/BII/2, August 7, 1987.

2 Wang Meng's novel, Huodong bian renxing (Moveable parts) (Beijing: Renmin Wenxue Chubanshe, 1987), is one of the first major works of fiction to directly confront this question. See also the review by Liu Zaifu, "Zhiai dao lengjun de jingshen shenpan" (The spiritual trial of going from sincere love to bitter harshness), Wenyibao, Juily 26, 1986.

3 Some Chinese critics see the search for the "national soul" as the main trend of all Chinese literature since 1977. See f.ex. Lei $\mathrm{Da}$, "Minzu linghun de faxian yu chongzhu" (The discovery and recast- 
ing of the national soul), Wenxue Pinglun, 1987, No. 1. For the root-seeking literature, see Goatkoei Lang-Tan, "Auf der Suche nach der verlorenen Identität. Zum Phänomen der 'Xungen Wenxue' in der chinesischen Gegenwartslitteratur (1984-1987)", Drachenboot, 1987, No. 1. For a critical view, see interview with Zhang Xinxin in Magazine Litteraire, 1987, No. 5. See also interview with Han Shaogong by Ni Yun, "Han Shaogong zhuzhang jianli 'wengexue" (Fian Shaogong suggests the establishment of "Cultural Revolution studies"), Zhengming, 1986, No. 11.

4 See f.ex. Wan Zhi (Chen Maiping), "Ziming zhong xia" (Under the striking clock), Renmin Wenxue, 1985, No. 9, originally published in Jintian wenxue yanjiuhui neibu jiaoliu ziliao zhier, 1980, and Shi Mo (Zhao Zhenkai), "Zai feixu shang" (In the ruins), Jintian, 1978, No. 1. See also Anne Wedell-Wedellsborg, "Chinese Modernism?" in Helmut Martin (ed.), Cologne 1984 Workshop on Contemporary Chinese Literature (Køln: Deutsche Welle, 1986).

5 This debate about Chinese national characteristics of course goes much further back. Before and around the turn of the century, the translators Lin Shu, Yan Fu, and later Liang Qichao, were deeply involved in the question.

6 In an interesting article the critic Su Ding distinguishes between three different attitudes in the works of younger writers: 1) The out-going one, finding oneself by changing the world (e.g. Zhang Chengzhi); 2) the introvert, transcending, "Chinese" one (e.g. A Cheng); 3) and the nihilist one of putting oneself outside the world (e.g. Liu Suola and Xu Xing). "Jinnian xiaoshuo zhong de san zhong rensheng zhuti bijiao" (A comparison among three types of human subjects in the fiction of recent years), Wenxue Pinglun, 1987, No. 3.

7 Colin Wilson, The Outsider (London:
Victor Gollarcz Ltd., 1956). I am indebted to this book for some of my ideas about the outsider character.

8 "Kuangren riji" (The diary of a madman), 1918.

9 "Chenlun", 1921. For modern interpretations of this story, see Wolfgang Kubin, "Yu Dafu (1896-1945): Werther und das Ende der Innerlichkeit", in Adrian Hsia (ed.), Goethe und China - China und Goethe (Bern 1984), and Michael Egan, "Yu Dafu and the Transition to Modern Chinese Literature", in Merle Goldman (ed.), Modern Chinese Literature in the May Fourth Era (Cambridge, Mass.: Harvard University Press, 1977).

10 Zhang Jie, "Ai shi bu neng wangi de", Beijing Wenyi, 1979, No. 11.

11 Zhang Kangkang, "Beijiguang", Shouhuo, 1981, No. 3. For an analysis, see Wolfgang Kubin, "Die Unruhe des Träumes", in Helmut Martin (ed.), op.cit.

12 Zhang Jie, "Fangzhou", Shouhuo, 1982, No. 2.

13 Zhang Xinxin, "Women zheige nianji de meng", Shouhuo, 1982, No. 4. Reprinted with debate in Zuopin yu Zhengming, 1983, No. 8. See also the female critic Wang Fei, "Zhang Xinxin xiaoshuo de neixin shijing yu waizai shijie" (Inner vision and outer world in the fiction of Zhang Xinxin), Wenxue Pinglun, 1986, No. 3.

14 See Anne Wedell-Wedellsborg, "Literature in the Post-Mao years", in Bob Benewick and Paul Wingrove (eds.), China in Transition (forthcoming).

15 Zhao Zhenkai, "Gaozhi shang de yueliang", Shouhuo, 1981, No. 5. It is translated into English in Zhao Zhenkai, Waves, transl. by Bonnie S. McDougall and Susette Ternent Cooke (Hongkong: The Chinese University Press, 1985). For a general analysis of Zhao Zhenkai's fiction, see Bonnie S. McDougall, "Zhao Zhenkai's Fiction: A Study in Cultural Alienation", Modern Chinese Literature, Vol. 1, No. 1, (1984). 
16 Norman Friedman, Form and Meaning in Fiction (Athens 1975), p. 256.

17 Ibid., p. 257.

18 Bei Dao (Zhao Zhenkai), "Xingfu dajie shisanhao", Shanxi Wenxue, 1985, No. 6. The original version of the story, including a scene in which the protagonist is put on trial, was published in the Peking University student magazine Weiminghu, 1980, No 1.

19 Ibid., p. 10.

20 Ibid., p. 9.

21 Can Xue, "Shanshang de xiaowu", Renmin Wenxue, 1985, No. 8. I am grateful to Susanne Posborg for first calling Can $X u e$ to my attention. For an introduction to Can Xue, see He Liwei, "Guanyu Can Xue nüshi" (On the writer Can Xue), Zuojia, 1987, No 2 .

22 See Bai Jieming's (Geremie Barmé) interview with Liu Xiaobo, "Zhongguo ren de jiefang zai ziwo juexing" (The liberalisation of the Chinese lies in self-awakening), Jiushi Niandai, 1987, No 3. Liu Xiaobo has published in Wenxue Pinglun and Zhongguo in 1985 and 1986, before the latter magazine was stopped. Some of his recent controversial articles and speeches are reprinted in Xinxibo, ed. by Dongbei Shifan Daxue Tushuguan Qingbao Bu, Nos. 3 and 4 where I have read them. In general, Chinese literary criticism and theory have developed greatly during the last 6 or 7 years. If articles by $\mathrm{Xu}$ Jingya, Sun Shaozhen and Xie Mian on the "menglongshi" ("obscure poetry") marked the beginning of post-Mao serious literary criticism, the literary scene is now swarming with young men (and women) trying to make a name for themselves in the field of genuine, nonpolitical, aesthetic criticism and theory. There are a number of different schools and directions; for a broad presentation of some tendencies, see Liu Zaifu, Wenxue de fansi (Literary reflections) (Beijing: Renmin Wenxue Chubanshe, 1986), pp. 1-39. This development has of course been greatly enhanced by the drastic increase in the knowledge of Western theories and critical approaches. A glance through f.ex. Dushu and Wenxue Pinglun of the last few years reveals articles on anything from new-criticism and structuralism to semiotics and deconstructionist theory. Of particular appeal seems to be what is broadly termed "literature and art psychology" (wenyi xinlixue) and in April 1987 a national conference on the subject was held in Zhengzhou.

23 Her stories include: "Gongniu" (The bull), Furong, 1985, No. 4; "Wu" (Fog), Wenxue Yuebao 1985, No. 6; "Kuangye li" (In the wilderness), Shanghai Wenxue, 1986, No. 8; "Canglao de fuyun" (Old clouds), Zhongguo, 1986, No. 5 (novella); "Wo zai nage shijie li de shiqing" (My affairs in that world), Renmin Wenxue, 1986, No. 11; "Tian chuang" (Window to heaven), Zhongguo, 1986, No. 8; "Xiuhuaxie ji Yuan si laoniang de fannao" (The embroidered shoes and the troubles of the old lady Yuan the Fourth), Hai'ou, 1986, No. 11;"A Mei zai yige taiyang li de chousi" (A Mei's worries in a sun), Tianjin Wenxue, 1986, No. 6; "Buguniao jiao de na yi shunjian" (The moment the cuckoo sang), Qingnian Wenxue, 1986, No. 4; "Meili nanfang zhi xiari" (Summer of the beautiful South), Zhongguo, 1986, No. 10; "Xiaoshuo liang ti" (Two stories), Qinghai Hu, 1987, No. 2; "Tiantang li de duihua" (Dialogue in Paradise), Hai'ou, 1987, No. 1; "Zhong zai zoulang shang de pingguoshu" (The apple tree planted in the corridor), Huacheng, 1987, No. 6 (novella) and "Tuwei biaoyan" (Breaking-out performance), Xiaoshuojie, 1988, No. 1 (novel).

24 Cheng Depei, one of the many interesting young literary critics in China today has called her fiction "a dialogue between the conscious and the subconscious" and described her method like this: starting out from the strictly sub- 
jective viewpoint of the narrator, then objectivizing the concepts and impressions of the narrator and finally turning these objectivized concepts and impresssions into targets for attack. "Zhemo Can Xue de meng" (The dreams which torment Can Xue), Shanghai Wenxue, 1987, No. 6, p. 72 .

25 For a rather negative evaluation of this and other works by Can Xue, see Wang Fei, "Zai meng de renshen zhong tongku jingluan" (Painful spasms in the gestation of dreams), Wenxue Pinglun, 1987, No. 5.

26 Can Xue, "Wushui shang de feizaopao", Wenxuebao, February 19, 1987.

27 For A Cheng and his life, see Zhong Chengxiang, "A Cheng qi ren" (Ah Cheng, the man), Renmin Ribao (haiwaiban), 14 instalments starting from January $6,1987$.

28 A Cheng, "Qiwang", Shanghai Wenxue, 1984, No. 7.
29 There are several opinions as to the Daoism of Wang Yisheng. Most Chinese critics regard him as a genuine Daoist. See e.g. Su Ding, "Que dao tian liang hao ge qiu" (Just say: cool weather (you mean) - what a fine autumn), Dushu, 1987, No. 5. Opposite views are f.ex. Huang Fengzhu (Ng Hong-chiok), "Shilun 'Qiwang"' (Tentative remarks on "The King of Chess"), Xianggang Wenxue, 1987, No. 2; reprinted in Drachenboot, 1987, No. 1; Huang thinks Wang Yisheng's desire to win is very un-Daoist, and that the story resembles a wuxia story. Liu Xiaobo finds the Daoism of "The King of Chess" to be only the "Confucianized type of Daoism", Xinxibo, No. 4 (see note 22).

30 For an orthodox, critical refutation of this, see Li Zhun, "Xiandai gudugan he shehuizhuyi wenyi" (The modern sense of loneliness and socialist literature and art), Guangming Ribao, July 30, 1987. 